\title{
LA CIUDAD DE VIGO EN EL CENTRO DE LOS ANÁLISIS DE GEOGRAFÍA URBANA EN GALICIA
}

\author{
Rubén Camilo Lois González
}

\begin{abstract}
RESUMEN
Las investigaciones de Geografía Urbana tienen un origen muy reciente en Galicia, pues sólo se contabilizan trabajos publicados en los últimos quince años. Destacan los análisis realizados sobre la ciudad de Vigo. En general la temática centrada en las ciudades, las villas y la comarcalización del territorio.
\end{abstract}

\begin{abstract}
Investigations about Urban Geography have a very recent origin in Galicia, because only works published in the last fifteen years are accounted. There are important studies about the city of Vigo. Generally, the theme use to be centred in towns, villages and country divisions.
\end{abstract}

La publicación, en los últimos meses de 1990, del estudio del geógrafo X. M. Souto González titulado «Vigo. Cen anos de historia urbana (1880-1980)» nos sirve como punto de partida a un conjunto de reflexiones que pretenden poner de manifiesto la creciente importancia que han adquirido las investigaciones sobre el fenómeno urbano gallego en los últimos tiempos. El protagonismo de las ciudades en la organización del territorio regional era un tema que prácticamente pasaba desapercibido en los estudios geográficos hasta finales de la década de los setenta. Por el contrario desde hace unos doce o trece años han empezado a proliferar las monografías orientadas a caracterizar la red urbana y el papel que algunos núcleos principales cumplen en la articulación del espacio, lo que justifica la conveniencia de que en el presente se acometan las primeras recapitulaciones bibliográficas provisionales sobre el estado general de estas aportaciones. A este respecto se debe de tener en cuenta que la ciudad de Vigo es el núcleo que ha merecido una mayor atención para el conjunto de científicos sociales que trabajan en Galicia (CARAMES 1979; PEREIRO 1981; ABREU 1983; SOUTO 1985; PRECEDO, RODRÍGUEZ Y VILLARINO 1988; SOUTO 1990). Asimismo tampoco podemos olvidar que X. M. Souto González (desarrollando unos enfoques muy distanciados de los del otro gran exponente de la geografía 
urbana gallega, el profesor A. Precedo Ledo) inaugura una serie de reflexiones globales sobre el proceso de urbanización en nuestra tierra (SOUTO 1982, SOUTO 1988), modelo teórico de análisis que influye directamente en numerosos trabajos elaborados recientemente (DURÁN, LOIS, LÓPEZ ELVIRA Y MONTOTO 1986; LOIS 1988; FERRAS 1991).

En líneas generales los estudios geográficos realizados sobre el hecho urbano regional pueden clasificarse en tres tipos bien diferenciados. Por una parte nos encontramos ante un conjunto de trabajos que se centran en caracterizar la organización comarcal del espacio gallego (PRECEDO 1974; SOUTO 1985; SOUTO 1988; LOIS 1988; ARMAS 1990) y otras investigaciones que, desde distintos puntos de vista, pretenden proponer un nuevo mapa político-administrativo de la región basándose en estas unidades supramunicipales (MIRALBES, TORRES y RODRÍGUEZ 1980; MIRALBES, RODRÍGUEZ, VILLARINO y ARMAS 1985; PRECEDO 1987; MELLA 1988). Se debe señalar que estas aportaciones tienen un enorme interés al subrayar que el municipio en Galicia posee una raigambre mucho menor que las comarcas, espacios de 20.000 a 60.000 habitantes que deben de construirse a partir de otras unidades territoriales simples (las parroquias), ya que se ha demostrado que las parroquias de numerosos municipios de la región pueden pertenecer a ámbitos comarcales diferentes (TORRES, PÉREZ y SANTOS 1989; LOIS 1990). Las aproximadamente cincuenta comarcas que se llegan a individualizar en el conjunto de las cuatro provincias casi siempre aparecen centralizadas por un núcleo urbano de escaso volumen demográfico y marcada terciarización (las «vilas» de 3.000 a 12.000 moradores y con un $70-75 \%$ de activos encuadrados en el sector servicios) y, de hecho, estos ámbitos supramunicipales constituyen las auténticas unidades de relación social y económica en las que se organiza el territorio gallego una vez constatado el progresivo declive de la realidad parroquial (la mejora en las vías de comunicación implica, entre otras cosas, que las prácticas colectivas de ocio dejen de realizarse en el marco de la parroquia y se articulen a partir de los pequeños núcleos ciudadanos distribuidos por todo el territorio). Si evidenciar el protagonismo de la comarca en la Galicia actual resulta sumamente útil, la realización de algunas propuestas de compartimentación del espacio en unidades comarcales cerradas parece una opción excesivamente precipitada pues en algunas investigaciones recientes se ha podido demostrar las enormes dificultades y contradicciones que conlleva delimitar con precisión las áreas de influencia de las «vilas» (LOIS 1988; LOIS 1990). Quizás el papel del geógrafo deba orientarse más a poner de manifiesto las realidades territoriales existentes, mientras que las propuestas efectivas de comarcalización son competencia de unas instituciones públicas que cuentan con medios suficientes para realizar detallados estudios previos, análisis donde hay que contar con el concurso de expertos procedentes de diversos campos de la ciencia social (y no sólo geógrafos).

Una segunda línea de investigación que ha seguido la geografía urbana gallega se refiere a la elaboración de monografías sobre las siete principales ciudades de la Comunidad Autónoma. Como hemos tenido ocasión de señalar, Vigo es el núcleo que más atención ha recibido no sólo desde la perspectiva del análisis territorial sino también por parte de economistas y arquitectos. Sin lugar a dudas el carácter eminentemente industrial de este núcleo, sus graves problemas urbanísticos y la existencia de amplios sectores de crecimiento edificativo difuso convierten a la «ciudad olívica» en un lugar atractivo de estudio para los distintos colectivos de científicos sociales. Frente a la relativa proliferación de aproximaciones al caso vigués, A Coruña, el otro gran centro rector de la trama urbana gallega aparece mucho menos atendido: sólo destacan algunas investigaciones realizadas sobre su área metropolitana (SANTOS 1986a; SANTOS 1986b; PRECEDO 1990) y un trabajo eminentemente descriptivo sobre la evolución de su plano (GONZÁLEZ-CEBRIÁN 1984). Por lo que respecta a las demás ciudades de la región (y si exceptuamos Ourense de la que 
apenas existen investigaciones urbanas), lo normal es encontrarnos ante una tesis o un trabajo exhaustivo que pretende reflejar algún aspecto de su realidad ciudadana. En este sentido conviene tener presente que de Santiago conocemos la localización de sus actividades terciarias (ARMAS 1989), de Ferrol su dependencia respecto a la industria de la construcción naval (CLEMENTE 1984), de Lugo el valor y usos del suelo urbano (RODRÍGUEZ LESTEGAS 1989) y de Pontevedra su evolución demográfica (PÉREZ FARIÑA 1985a). De hecho la realización de este significativo conjunto de trabajos ya ha permitido elaborar alguna breve síntesis (PÉREZ FARIÑA 1985b; SOUTO 1988) sobre los rasgos definitorios de los principales núcleos urbanos de la región.

Un tercer grupo de trabajos se centra en el análisis de las «vilas», cabeceras económicas indiscutibles de los espacios comarcales que a pesar de poseer unos volúmenes de población absoluta poco importantes nada tienen que ver con los asentamientos de carácter rural. Este conjunto de pequeños centros ciudadanos han sido analizados, en la mayoría de las ocasiones, de forma aislada y mediante breves artículos (PÉREZ IGLESIAS 1978; Equipo XEGA 1980; RODRÍGUEZ FACAL 1983; PENAS 1988; VILLOCH 1988). Sólo en muy pocos casos se realizan estudios sobre el «sistema de vilas» en espacios de características homogéneas (RODRÍGUEZ CUDEIRO 1983; TORRES y LOIS 1992) y la publicación de monografías relativamente amplias sobre el tema se reduce a tres ejemplos de características desiguales (DURÁN, LOIS, LÓPEZ ELVIRA y MONTOTO 1986; GARCÍA VIDAL 1989; VILLOCH 1990). De hecho, las dificultades inherentes a los análisis microespaciales desaniman la realización de este tipo de trabajos; en estas investigaciones se trata de evidenciar unos rasgos urbanos (formación de sectores especializados dentro del plano, actuación de agentes sociales muy diversos, etc.) típicos de estas localidades de escasa entidad. Sobre el reducido número de trabajos de esta temática también se debe de tener en cuenta que la década de los ochenta supone más una fase inicial en la aproximación al mundo ciudadano gallego (lo urgente es, bien caracterizar todo el espacio, bien realizar las primeras obras sobre las grandes ciudades) que un período de madurez para las investigaciones de geografía urbana (en los próximos años es deseable que se inicien análisis de los amplios espacios periurbanos y rururbanos de nuestra tierra, así como una profundización de los trabajos que se centren en la realidad «vilega» y comarcal).

Seguramente pueda haber sorprendido que junto a las investigaciones referidas a las principales ciudades o al «fenómeno vilego» hayamos incluido, como trabajos de geografía urbana, una serie de aproximaciones centradas en caracterizar la realidad comarcal. En este sentido cabe señalar que si bien los intentos de definir una organización del territorio gallego a partir de espacios supramunicipales no son estrictamente asimilables a las reflexiones que se realizan sobre el hecho urbano, en el caso de nuestra región es preciso poner de manifiesto la profunda vinculación que existe entre los artículos y libros orientados hacia estos temas. Por una parte se debe de considerar que muchos de los autores que han realizado estudios sobre algún núcleo urbano concreto (PRECEDO et alt. 1988; PRECEDO 1900; SOUTO 1990) se dedican también a analizar la organización comarcal en las cuatro provincias (PRECEDO 1974; PRECEDO 1987; SOUTO 1985; SOUTO 1988). De hecho los estudios que se centran en definir los rasgos urbanos en un único núcleo son el sustento de caracterizaciones generales sobre la organización del territorio. Por otra parte las investigaciones sobre comarcalización introducen una lectura eminentemente urbana de la realidad gallega actual. Frente a la imagen de un espacio rural, agrario y basado en estructuras precapitalistas (sería la formulación del atraso económico que desarrolla BEIRAS en 1972), comienzan a aparecer las interpretaciones que definen a Galicia como un territorio urbanizado. Territorio que registra un rápido e incompleto proceso de urbanización (SOUTO 1988; BERTRAND 1992), que responde a decisiones tomadas fundamen- 
talmente en el exterior. A pesar de las imágenes tópicas que se pueden haber ido creando a lo largo de mucho tiempo, hoy en día es indiscutible la plena integración de nuestra tierra en un marco económico mucho más amplio (estatal y continental), así como el rápido proceso de crecimiento de las ciudades y, sobre todo, de los sectores periurbanos y rururbanos. El porcentaje de activos en el sector primario continúa siendo muy elevado (próximo al 40\%), no obstante la subordinación de las actividades agrarias al trabajo en la industria, la construcción y los servicios se va haciendo cada vez más evidente como lo demuestra el hecho de la reciente expansión de la «agricultura a tiempo parcial» bajo fórmulas diversas. A este respecto conviene recordar que el municipio gallego con más agricultores censados es Vigo y que en muchos territorios de Pontevedra y Ourense más del 30\% de los titulares de explotaciones agrícolas se asocian a una actividad principal fuera del campo (TORRES y LOIS 1992).

Como ha venido siendo normal en la evolución de nuestra ciencia, los nuevos enfoques que se desarrollan en el análisis espacial hay que vincularlos necesariamente a reflexiones coetáneas que llevan a cabo los historiadores y los economistas. Concretamente en Galicia los últimos años suponen tanto un interés creciente por los análisis urbanos e industriales no sólo en la geografía (destacar los trabajos de LÓPEZ ALSINA sobre vida ciudadana en el medievo o, en un campo muy diferente, las interpretaciones sobre el proceso industrializador de CARMONA, LÓPEZ FACAL o ALONSO por citar a tres autores de características perfectamente individualizadas), como la aparición de nuevas lecturas sobre la aparente ausencia de transformaciones en la estructura productiva regional (las tesis del atraso económico son contradichas por COLINO y PÉREZ TOURIÑO desde la perspectiva del análisis económico y por VILLARES, FERNÁNDEZ PRIETO, BALBOA y QUINTANA en una serie de trabajos de historia contemporánea). De lo que se trata es de superar las anteriores concepciones del «atraso económico» y poner de manifiesto que la sociedad gallega optó por todo tipo de innovaciones y procesos de adaptación que revirtieran en mejoras productivas y de nivel de vida generales. El atraso y las particularidades del espacio gallego no son tanto el resultado de unas relaciones de sometimiento como la consecuencia de una serie de factores endógenos (ausencia de una clase burguesa con voluntad renovadora) y de las limitaciones implícitas al desarrollo del capitalismo en todo el Estado (limitaciones que se hacen mucho más evidentes en un espacio aislado y «excéntrico» como el de nuestra región). De hecho, a partir de mediados de siglo la llegada de empresas multinacionales y la adopción de un modelo dirigista de industrialización (dicho de otro modo, la plena incorporación de Galicia a un marco económico crecientemente interrelacionado a escala internacional) supondrá una reordenación del territorio en profundidad, en un proceso todavía inacabado (BERTRAND 1992) y que se resume en el término «urbanización» (SOUTO 1988).

En la actualidad son escasísimos los científicos sociales que se oponen a reconocer el hecho de que nuestra región ha registrado un proceso urbanizador en épocas recientes. En el campo de la geografía la unanimidad a este respecto es casi total, si bien es posible diferenciar dos corrientes interpretativas a la hora de analizar el sistema de ciudades y núcleos principales de las cuatro provincias. Por una parte PRECEDO LEDO (las claves de su interpretación pueden examinarse en sus obras de 1987 y 1990), inicia sus argumentaciones enmarcando a la red urbana gallega en un ámbito territorial más amplio (utilización de clasificaciones jerárquicas de ciudades de todo el Estado). Asimismo este autor (siguiendo los modelos de planificación regional desarrollados en Francia en la década de los cincuenta y sesenta) otorga a la ciudad de A Coruña un papel predominante en la articulación del espacio (se la califica como «metrópoli regional»), frente a una posición secundaria de Vigo («metrópoli complementaria») y de Santiago (recientemente potenciada como centro político-administrativo). Las restantes urbes se explican a partir de 
sus vinculaciones con estos tres núcleos principales (Pontevedra en relación a Vigo, Ferrol y menor medida Lugo en función de A Coruña, etc.) y las «vilas» que ejercen como cabeceras comarcales se caracterizan de forma homogénea obviando posibles diferenciaciones que puedan surgir dentro de este grupo de asentamientos (sólo se individualizan aquellas pequeñas entidades urbanas que se incluyen en un área metropolitana determinada). Las posiciones de PRECEDO LEDO otorgan una gran importancia a la idea de jerarquía en los núcleos urbanos, además subyace un pensamiento tecnocrático en buena parte de su argumentación: se analiza el sistema de ciudades en la medida en que las administraciones públicas y la iniciativa privada van a utilizar las informaciones aportadas por el geógrafo para planificar e invertir a corto o medio plazo. A nuestro juicio, las importantes contribuciones que realiza este autor tienden a devaluarse por sus continuas apelaciones a la supremacía de A Coruña (las percepciones subjetivas llegan a recubrirse con técnicas de cuantificación aparentemente asépticas) en el marco de la jerarquía urbana regional.

Por lo que respecta a las posiciones de SOUTO GONZÁLEZ (consultar especialmente su trabajo de 1988), cabe señalar que este geógrafo analiza el proceso de urbanización en Galicia sin considerar que se asocie claramente a la evolución registrada en el resto de España. Las decisiones adoptadas en Madrid y en los centros de poder de otras ciudades del occidente europeo son claves para comprender los cambios acaecidos recientemente en la organización del espacio regional (básicamente se defiende que las transformaciones producidas son de origen exógeno); sin embargo, se mantiene que todo este conjunto de mutaciones que han tenido lugar en el territorio no eliminan la personalidad propia de Galicia en el marco estatal y/o continental. Este autor considera que la trama urbana regional presenta dos claros centros rectores de rasgos muy similares: A Coruña y Vigo. Tanto una ciudad como otra tienden a articular sendas regiones urbanas donde se incluyen otras ciudades funcionalmente especializadas (Pontevedra y Ferrol), diversas «vilas» (Cangas, O Porriño, Sada, Betanzos, etc.) y amplios sectores periurbanos (Oleiros, Culleredo, Nigrán, Redondela, etc.). Se trataría de poner de manifiesto la complementariedad entre el gran núcleo del Norte (A Coruña) y la ciudad articuladora de todo el sur de la región (Vigo), dos localidades que se han desarrollado en el marco de una economía capitalista crecientemente interrelacionada y que muestran evidentes rasgos coincidentes. La división del espacio gallego en una realidad septentrional y otra meridional no se produce dada la localización intermedia de Santiago de Compostela entre los núcleos vigués y coruñés. La capital de la Comunidad Autónoma se define como un núcleo rector del interior que se especializa en determinadas funciones de amplio alcance (centro administrativo, universitario, hospitalario y del turismo cultural). De hecho entre A Coruña y Vigo se localizan las comarcas más ricas y pobladas de Galicia, espacios que se disponen de Norte a Sur extendiéndose por buena parte del occidente regional. En el interior de Galicia las ciudades de Lugo y Ourense actúan de centros indiscutibles para la articulación de un espacio esencialmente agrario, menos poblado y con un inferior nivel de renta. La ligazón de estas dos capitales de provincia con A Coruña, Vigo o Santiago es indiscutible, si bien se prefiere reafirmar su protagonismo como cabeceras de amplios territorios. Dentro de la interpretación de SOUTO GONZÁLEZ comienzan a matizarse algunas diferencias que se detectan entre los distintos «núcleos vilegos» y no sólo en función de su pertenencia o no a una área metropolitana concreta. Siguiendo una serie de trabajos realizados en regiones próximas a Galicia (fundamentalmente el de MURCIA NAVARRO en 1981) comienza a referirse a «vilas litorales en proceso de industrialización», «vilas especializadas funcionalmente», etc., en una primera aproximación general al tema que será preciso completar con futuras aportaciones mejor documentadas (recordemos la escasez de trabajos publicados hasta el momento sobre las cabeceras comarcales). Por último hay 
que tener en cuenta que si SOUTO GONZÁLEZ prefiere recurrir al examen de procesos (reivindicación del materialismo histórico) PRECEDO LEDO opta preferentemente por los análisis del presente, lo que en parte supone una oposición entre el deductivismo del primero y la tendencia a cimentar la exposición en aproximaciones empíricas del segundo.

La importancia de la teoría, en concreto del materialismo histórico como fundamento para el estudio de un proceso de crecimiento urbano, se pone claramente de manifiesto en la obra recién publicada de SOUTO GONZÁLEZ (Vigo. Cen anos de historia urbana (18801980)) a la que aludimos desde un comienzo. Este libro de X. M. Souto trasciende, en muchos aspectos, su intención original de servir de caracterización a un modelo de expansión edificativa en una de las dos principales ciudades gallegas. Junto a la última obra publicada de A. Precedo (La Coruña. Metrópoli regional), supone la culminación de un primer decenio de trabajos sobre el hecho ciudadano en Galicia realizados desde la perspectiva del análisis territorial. La investigación de Souto (en origen su tesis doctoral) aporta, antes que nada, un intenso trabajo de selección bibliográfica donde se aprovechan las numerosas contribuciones que la ciencia social ha realizado sobre el núcleo vigués (en A Coruña o Santiago este trabajo no podría acometerse por la ausencia de una gama de investigaciones disponibles tan amplia). En segundo lugar, este libro que refleja una metodología relativamente arraigada en el campo de los estudios de geografía urbana (las influencias de HARVEY, CASTELLS y CAPEL son evidentes) viene a ser la culminación de todos los análisis sobre las ciudades gallegas que se realizan en nuestra región durante los años ochenta. Quizás pueda parecer algo exagerada esta consideración, pero debemos de valorar que los modelos historicistas que llegan a recurrir a la utilización frecuente de técnicas cuantitativas conforman el grueso de las aportaciones realizadas hasta el presente. Es cierto que el materialismo histórico es una base escasamente utilizada en estudios previos, sin embargo el propio carácter del trabajo como el análisis evolutivo más documentado sobre una urbe principal, su entronque con las corrientes clásicas de la geografía urbana (desde Blanchard hasta Harvey pasando por los enfoques teoréticos) y su intento de aprehender la compleja realidad socio-espacial de una localidad de un cuarto de millón de habitantes (definición de un objetivo ambicioso), individualizan a esta obra de casi setecientas páginas como la culminación de muchas de las búsquedas que han llevado a cabo los estudiosos del hecho urbano en Galicia durante los últimos años.

Acabamos de significar que el reciente trabajo de X. M. Souto implica una «culminación», porque se trata de un estudio muy completo y también porque nos hallamos ante un modelo de análisis espacial del fenómeno urbano gallego que deberá ser superado y/o enriquecido en los próximos años. El tema objeto de esta investigación, una de las grandes ciudades de la región, necesariamente tendrá que ir perdiendo importancia en la geografía urbana que se elabore en Galicia durante los próximos años. Hoy en día existe una aceptable base bibliográfica de caracterización de al menos seis de los siete núcleos gallegos que superan los cincuenta mil habitantes. Seguramente seguirán apareciendo monografías en torno a ellos que aporten nuevos datos sobre su dinámica interna, no obstante es preciso que en los próximos tiempos los sectores periurbanos, las cabeceras comarcales y las relaciones interurbanas ocupen buena parte del protagonismo de futuros estudios. En segundo lugar, los nuevos enfoques que se aplican en el análisis territorial demuestran que la percepción subjetiva del espacio urbano, que es ante todo un espacio vivido por personas con diferente nivel de movilidad, tendrán que ir introduciéndose en nuevas aproximaciones a realizar sobre el hecho urbano en la región. La obra de X. M. Souto incluye numerosas referencias nominales a destacados protagonistas que se sucedieron en la configuración del Vigo actual (alcaldes, promotores inmobiliarios, financieros, etc.), sin embargo cada uno de estos personajes juega un papel prefijado en función de su 
posición social. Independientemente de que las observaciones de Souto sean en numerosas ocasiones atinadas, cada vez se hace más necesario hacer entrar al individuo y su espacio vital cotidiano en estas amplias monografías geográficas centradas en la caracterización de lo urbano. A modo de conclusión consideramos imprescindible valorar que si bien los estudios geográficos del mundo ciudadano gallego han irrumpido brillantemente en los último años en el panorama científico regional ayudando a reinterpretar las bases en las que se cimenta la organización del territorio, es preciso que en los próximos tiempos se produzca una ampliación en la temática de geografía urbana hasta ahora abordada y que los nuevos modelos introducidos en nuestra ciencia comiencen a ser utilizados en reflexiones elaboradas sobre y desde Galicia.

\section{Referencias bibliográficas}

ABREU FERNÁNDEZ, L. F. (1983): La formación de capital en la Ría de Vigo (1880-1940). El sector naval y la industria conservera. Santiago. Tesis doctoral (inédita).

ALONSO ÁLVAREZ, L. (1976): Industrialización y conflictos sociales en la Galicia del Antiguo Régimen. Madrid.

ARMAS DIÉGUEZ (1989): Análise xeográfica das actividades terciarias compostelás. Santiago.

- (1990): La organización del espacio lucense. 2 vols. Lugo.

BALBOA LÓPEZ, X. (1990): $O$ monte en Galicia. Vigo.

BEIRAS TORRADO, X. M. (1972): O atraso económico de Galicia. Vigo.

BERTRAND, J. R. (1992): A poboación de Galicia. Estudios xeográficos. Santiago.

CAPEL SÁEZ, H. (1974): Agentes y estrategias en la producción del espacio urbano español, en Revista de Geografía, vol. VIII, núms. 1-2. Barcelona.

CARAMÉS VIÉITEZ, L. (1979): La hacienda del municipio de Vigo. Perspectiva histórica y situación actual. Santiago. Extracto Tesis Doctoral.

CARMONA BADÍA, X. (1983): Producción textil rural y actividades marítimo-pesqueras en Galicia. 1750-1905. Santiago. Tesis Doctoral.

- (1990): El atraso industrial de Galicia. Barcelona.

CASTELLS, M. (1974): Problemas de investigación en sociología urbana. Madrid.

- (1979): La cuestión urbana. Madrid.

CLEMENTE CUBILLAS, E. (1984): Desarrollo urbano y crisis social en Ferrol. Salamanca.

COLINO SUEIRAS, X. y PÉREZ TOURIÑO, E. (1983): Economía campesiña e capital. A evolución da agricultura galega. 1960-1980. Vigo.

DURÁN VILLA, F. R.; LOIS GONZÁLEZ, R. C.; LÓPEZ ELVIRA, M. J.; MONTOTO QUINTEIRO, J. (1986): Viveiro. Achegamento á realidade dun núcleo urbano galego. Santiago.

FERNÁNDEZ PRIETO, L. (1988): A Granxa Agricola-Experimental da Coruña (1888-1928). Contribución ao estudio da renovación técnica da agricultura galega. Santiago.

FERRAS SEXTO, C. (1991): O desenvolvimento urbanístico e económico de Fene durante os séculos XIX e XX. Santiago. Memoria de Licenciatura (inédita).

GARCÍA VIDAL, P. (1989): Noia: xeografía urbana e área de influencia. Noia.

GONZÁLEZ-CEBRIÁN TELLO, J. (1984): La ciudad a través de su plano. La Coruña. A Coruña.

HARVEY, D. (1978): Urbanismo y desigualdad social. Madrid.

LOIS GONZÁLEZ, R. C. (1988): Educación e territorio en Galicia: as áreas de influencia dos Institutos de Bacharelato e o seu impacto na comarcalización, en Actas do Simposio Internacional «Otero Pedrayo e a Xeografía de Galicia». Santiago.

- (1990): Aproximación a una geografía de la juventud: estudio socio-espacial de los centros de enseñanzas medias y universitarias en Galicia (1960-1990). Tesis Doctoral (inédita).

LÓPEZ ALSINA, F. (1976): Introducción al fenómeno urbano medieval gallego a través de tres ejemplos: Mondoñedo, Ribadeo y Vivero. Santiago.

LÓPEZ FACAL, X. (1977): Desarticulación y dependencia industrial de Galicia. Santiago.

MELLA MARQUES, X. M. (1988): Alternativas para una comarcalización de Galicia, en I $I^{\mathbf{a}}$ Xor- 
nadas sobre A Comarcalización na Ordenación do Territorio, Asociación galega de ciencia rexional. Santiago.

MIRALBES BEDERA, M..$^{\mathrm{a}} \mathrm{R}$.; TORRES LUNA, M. ${ }^{\mathrm{a}} \mathrm{P}$. de y RODRÍGUEZ MARTÍNEZ-CONDE, R. (1980): Aproximación a una división comarcal de Galicia. Santiago.

MIRALBES BEDERA, M. ${ }^{a}$ R.; VILLARINO PÉREZ, M.; ARMAS DIÉGUEZ, P. y RODRÍGUEZ MARTÍNEZ-CONDE, R. (1985): Galicia. Unha división comarcal do seu espacio, en I Cuaderno de Xeografía. A Coruña.

MURCIA NAVARRO, E. (1981): Las villas costeras en el sistema urbano asturiano. Oviedo.

PENAS MURIAS, M. ${ }^{a}$ V. (1988): Caracterización socio-demográfica del municipio de Narón (La Coruña), en Actas do Simposio Internacional «Otero Pedrayo e a Xeografía de Galicia». Santiago. PEREIRO ALONSO, J. L. (1981): Deterioro y desarrollo urbano de la ciudad de Vigo. Santiago.

PÉREZ FARIÑA, M. ${ }^{a}$ L. (1985a): La ciudad de Pontevedra. Evolución histórica y demográfica. Santiago.

- (1985b): El fenómeno urbano, en Geografía de Galicia dirigida por Torres Luna, M. ${ }^{\mathrm{a}} \mathrm{P}$. de, Vol. II. A Coruña.

PÉREZ IGLESIAS, M. ํ L. (1978): Estructura demográfica del municipio de Villagarcía. Santiago.

PRECEDO LEDO, A. (1974): Galicia, red urbana y desarrollo regional, en «Boletín de la Real Sociedad Geográfica», vol. CX, núms. 1-12.

- (1987): Galicia: estructura del territorio y organización comarcal. Santiago.

PRECEDO LEDO, A.; RODRÍGUEZ MARTÍNEZ-CONDE, R. y VILLARINO PÉREZ, M. (1988): Vigo, área metropolitana. Vigo.

PRECEDO LEDO, A. (1990): La Coruña, metrópoli regional. A Coruña.

QUINTANA GARRIDO, X. R. (1990): Campesinos que se adaptan y agricultura que se mueve. De la historia agraria de la Galicia contemporánea, en «Áreas. Revista de Ciencias Sociales», núm. 12.

RODRÍGUEZ CUDEIRO, M. (1983): Los lugares centrales en la mitad septentrional de la Meseta lucense. III Coloquio Ibérico de Geografía. Barcelona.

RODRÍGUEZ FACAL, M. ${ }^{\text {T }}$ T. (1983): Betanzos. Desarrollo actual. III Coloquio Ibérico de Geografía. Barcelona.

RODRÍGUEZ LESTEGAS, F. (1989): Valor y usos del suelo urbano en Lugo. Santiago.

SANTOS LEDO, M. J. (1986a): Algunos aspectos teórico-conceptuales en el estudio del área metropolitana de La Coruña, en «Revista del Instituto José Cornide de Estudios Coruñeses», año XXII, núm. 22. A Coruña.

- (1986b): Estudio de localización industrial. El caso de La Coruña, en «Revista del Instituto José Cornide de Estudios Coruñeses», año XXII, núm. 22. A Coruña.

SOUTO GONZÁLEZ, X. M. (1982): Encol do hábitat e do poboamento. O caso de Galicia, en «Cuadernos de Estudios Gallegos», núm. 98. Santiago.

- (1985): O problema da rexionalización en Galicia. Encol da rexión urbana de Vigo, en «I Caderno de Xeografía. Sociedade Galega de Xeografía». A Coruña.

- (1988): Xeografía Humana. Vigo.

- (1990): Vigo. Cen anos de historia urbana (1880-1980). Vigo.

TORRES LUNA, M.ํㅗ P. de (1985): Geografía de Galicia. A Coruña.

TORRES LUNA, M. ${ }^{\underline{a}}$ P. de; PÉREZ FARIÑA, M..$^{\underline{a}}$ L. y SANTOS SOLLA, J. M. (1989): Municipios y parroquias de Galicia. Santiago.

TORRES LUNA, M. ․ P. de y LOIS GONZÁLEZ, R. C. (1991): Las explotaciones agrarias en Galicia. Homenaje al Prof. L. M. Albentosa. Tarragona (en prensa).

- (1992): Le rôle des bourgs dans la montagne de Galice (Espagne). Homenage al Prof. André Fel. Clermont-Ferrand.

VILLARES PAZ, R. (1982): La propiedad de la tierra en Galicia (1500-1936). Madrid.

VILLOCH VÁZQUEZ, M. ․ P. (1989): Foz: análisis de la estructura demográfica de una villa costera lucense, en Actas do Simposio Internacional «Otero Pedrayo e a Xeografía de Galicia». Santiago.

- (1990): Estudio demográfico del municipio de Foz. Lugo.

XEGA, Equipo (1980): O proceso urbano en Galicia, os casos de Baiona, Cée e Xinzo de Limia, en «Grial», núm. 68. Vigo. 